\title{
Comportamento do cimento supersulfatado (CSS) obtido a partir de escórias de alto forno geradas a carvão vegetal e mineral e sujeito à cura térmica
}

\author{
Behavior of supersulfated cement (SSC) \\ obtained from blast furnace slag generated \\ by charcoal and coke and submitted to \\ thermal curing
}

Cheila Sirlene Beutler ${ }^{1}$, Caroline Angulski da Luz ${ }^{1,2}$, Janaina Sartori Bonini ${ }^{2}$

\author{
${ }^{1}$ Departamento de Engenharia Civil - UTFPR CP: 571 - 85503-390, Pato Branco, PR, Brasil. \\ e-mail: cheilabeutler@alunos.utfpr.edu.br \\ ${ }^{2}$ Programa de Pós-graduação em Engenharia Civil - PPGEC/UTFPR CP: 571 - 85503-390, Pato Branco, PR, Brasil. \\ e-mail: angulski@utfpr.edu.br, janainabonini@utfpr.edu.br
}

\section{RESUMO}

O uso de escórias de alto forno (EAF) como matéria-prima em cimento Portland (CP) tem sido considerado há décadas visando à redução da emissão de $\mathrm{CO}_{2}$ e da exploração de reservas de calcário e argila envolvidos na produção do clínquer. Recentemente, o interesse por cimentos isentos ou com baixo teor de clínquer tem crescido, como é o caso de cimentos supersulfatados (CSS), os quais são compostos majoritariamente por escórias de alto forno, em até $90 \%$. As características químicas exigidas para a escória para uso em CSS, no entanto, não são as mesmas exigidas para uso em CP. Uma das características mais importantes das escórias é a relação do teor de $\mathrm{CaO}$ e $\mathrm{SiO}_{2}$. Escórias geradas em fornos a carvão vegetal, apresentam relação $\mathrm{CaO} / \mathrm{SiO}_{2}$ baixa, sendo assim consideradas ácidas e aquelas geradas em fornos a carvão mineral são consideradas básicas. Este trabalho tem por objetivo avaliar o comportamento do CSS obtido de duas escórias, A e B, geradas em fornos a carvão vegetal e mineral. A cura térmica também foi empregada como forma de intensificar a cinética de hidratação e aumentar as propriedades mecânicas. Os resultados mostraram que, embora ambas as escórias atendessem às condições estipuladas pela norma europeia (EN 15743), a B se mostrou mais adequada para uso em CSS. Através da cura térmica à $40{ }^{\circ} \mathrm{C}$, foi possível aumentar a formação de silicato de cálcio hidratado (CSH) e consequentemente a resistência mecânica do CSS feito com escória A. O menor teor de cálcio da escória A foi a provável causa da sua baixa reatividade.

Palavras-chave: cimento supersulfatado, escória de alto forno, cura térmica.

\section{ABSTRACT}

The use of blast furnace slag (BFS) as a raw material in Portland cement (PC) has been considered for decades to reduce $\mathrm{CO}_{2}$ emissions and the exploitation of limestone and clay reserves involved in clinker production. Recently, interest in free or low clinker cements has grown, such as supersulfated cements (SSC), which are composed mostly of blast furnace slag, up to $90 \%$. The chemical characteristics required for slag for use in SSC, however, are not the same as those required for use in PC. One of the most important characteristics of the slag is the ratio of the $\mathrm{CaO}$ and $\mathrm{SiO}_{2}$ content. Slags generated in charcoal kilns have a low $\mathrm{CaO} / \mathrm{SiO}_{2}$ ratio and are considered acidic and those generated in coal kilns are considered basic. This study aims to evaluate the behavior of SSC obtained from two slag, A and B, generated in kilns with charcoal and mineral. Thermal curing was also used to improve the hydration kinetics and mechanical properties. The results showed that, although both slags met the standard limits of (EN 15743), the B was more suitable for use in SSC. Using thermal cure at $40{ }^{\circ} \mathrm{C}$, it was possible to increase the formation of calcium silicate hydrate (CSH) and consequently the mechanical resistance of the SSC made with slag A. The lower calcium content of slag A was the probable cause of its low reactivity. 
Keywords: supersulfated cement, blast furnace slag, thermal cure.

\section{INTRODUÇÃO}

O uso de adições em cimentos Portland tem sido considerado, há décadas, em vários países, cujo principal objetivo é reduzir a quantidade de clínquer. Entre as adições mais utilizadas, destaca-se a escória de alto forno (EAF), a qual é resultante da produção do ferro gusa. Assim, além do reaproveitamento deste subproduto, ocorre a redução da emissão de $\mathrm{CO}_{2}$ para a atmosfera durante o processo de produção do clínquer e, também, a diminuição da exploração de reservas naturais de calcário e argila, que são matérias-primas do clínquer Portland.

No Brasil, a NBR 16697 [1] permite que a EAF seja empregada em até 75\% para compor o cimento tipo CP III, enquanto a norma americana (ASTM) [2] e britânica (BSI) [3] adotam 70 e 60\%, respectivamente, podendo a última chegar em $85 \%$, para a produção de cimento de alto forno com baixo calor de hidratação.

Mais recentemente, além do uso de matérias-primas alternativas, também se tem observado o crescente interesse por cimentos alternativos ao Portland, caracterizados pela ausência, ou baixo teor de clínquer na sua composição, como os cimentos álcali ativados e cimentos supersulfatados (CSS), os quais podem ser compostos majoritariamente por escórias de alto forno. Neste sentido, novas pesquisas destinadas ao estudo de EAF têm surgido visando ao seu emprego em cimentos especiais, e não somente em cimentos do tipo Portland [4-6].

O cimento supersulfatado (CSS) é composto por até $90 \%$ de escória de alto forno, além de 10 a $20 \%$ de sulfato de cálcio, geralmente na forma anidra $\left(\mathrm{CaSO}_{4}\right)$ e até $5 \%$ de ativador alcalino, que pode ser clínquer ou cimento Portland, ou hidróxidos [5, 6]. O CSS foi empregado na Europa, principalmente após a Segunda Guerra Mundial, mas mudanças no processo de fabricação do ferro gusa implicaram a redução do teor de alumina na EAF, fazendo com que a mesma fosse direcionada para a produção de cimento Portland. Em 2010, no entanto, a norma europeia disponibilizou a EN 15743 [7], que se refere às novas especificações e conformidades do CSS, fazendo com que o interesse por este cimento voltasse a crescer. Além de propriedades ambientais, o CSS apresenta boa resistência mecânica e ao ataque por sulfato, além de baixo calor de hidratação [8].

As características químicas exigidas para a EAF em CSS, no entanto, não são as mesmas exigidas para uso em CP. Enquanto no cimento Portland a escória reage com ela própria (e/ou com hidróxido de cálcio) para formar CSH, no CSS, a escória reage com o sulfato para forma CSH e também etringita, conforme Equação 1 simplificada [5-10].

$$
C_{5} S_{3} A+C H+3 C \bar{S}+34 H \rightarrow C_{6} A \bar{S}_{3} H_{32}+3 C S H
$$

A escória de alto forno (EAF) é obtida nas siderúrgicas, no processo de redução do minério de ferro, e sua composição química é bastante dependente do tipo de combustível (carvão mineral ou vegetal) utilizado na produção do ferro gusa. Seus principais compostos são o óxido de sílica $\left(\mathrm{SiO}_{2}\right)$, óxido de alumínio $\left(\mathrm{Al}_{2} \mathrm{O}_{3}\right)$ e óxido de cálcio $(\mathrm{CaO})$, em proporções diferentes às do Cimento Portland. $\mathrm{O} \mathrm{SiO}_{2}$ e o $\mathrm{Al}_{2} \mathrm{O}_{3}$ são provenientes do minério, enquanto o $\mathrm{CaO}$ provém do calcário utilizado como fundente [11-12].

Uma das características mais importantes das EAF's é a relação do teor de $\mathrm{CaO}$ e $\mathrm{SiO}_{2}$, também conhecida por índice de basicidade simplificado. A importância do $\mathrm{CaO}$ e de sua proporção é denotada na retirada de enxofre originário do carvão mineral. Em fornos a carvão vegetal, sua importância é secundária, uma vez que este tipo de combustível contém baixo índice de enxofre. Portanto, escórias obtidas de fornos de carvão vegetal geralmente apresentam relação $\mathrm{CaO} / \mathrm{SiO}_{2}$ baixa, sendo assim consideradas ácidas. As escórias provenientes de fornos de carvão mineral (coque) são consideradas básicas, tendo em vista a necessidade de grande percentual de $\mathrm{CaO}$ para a retirada do enxofre presente. Comumente, encontra-se na literatura a seguinte relação: $\mathrm{CaO} / \mathrm{SiO}_{2}<1$ Escórias Ácidas e $\mathrm{CaO} / \mathrm{SiO}_{2}>1$ Escórias Básicas [12].

$\mathrm{O}$ uso de EAF em cimentos Portand tem sido condicionado aos módulos de basicidade (MB), no caso da NBR 16697 [1] de $\mathrm{CaO}+\mathrm{MgO}+\mathrm{Al}_{2} \mathrm{O}_{3} / \mathrm{SiO}_{2}>1$, o que faz com que aquelas geradas em fornos a carvão vegetal sejam menos empregadas. A escolha da EAF através do MB, entretanto, é considerada pela literatura muito simplista [5]. Com o surgimento de cimentos especiais à base de escória, vem crescendo também a necessidade de ampliação da base científica acerca das características químicas das escórias visando, sobretudo, ao uso mais racional da matéria-prima. Trabalhos recentes mostram que uma mesma escória pode ser adequada para cimento supersulfatado, mas inadequada para Portland ou álcali ativados e vice-versa [4, 13, 14]. 
Também em trabalhos recentes sobre o uso da EAF em cimentos supersulfatados (CSS), a investigação sobre o efeito do teor de alumina tem sido destacada [5,6]. Pelo fato da etringita ser um dos principais compostos hidratados em CSS, escórias com teores mais elevados de alumina, superior a 10\%, são preferidas [5]. Entretanto, tem-se constatado que EAF com menores teores de alumina também podem produzir CSS com alta resistência mecânica (superior a $40 \mathrm{MPa}$ ) [14-15].

O uso de cura térmica também foi investigado por ANGULSKI DA LUZ e HOOTON [6] como forma de aumentar as propriedades mecânicas do CSS em escórias com baixo teor de alumina (8\%). Os autores identificaram que temperaturas mais altas $\left(40^{\circ} \mathrm{C}\right)$ podem ser mais nocivas ao CSS que temperaturas baixas $\left(15^{\circ} \mathrm{C}\right)$ devido à baixa solubilidade do sulfato de cálcio em temperaturas mais elevadas.

Neste contexto, este trabalho avaliou o comportamento do CSS obtido de duas escórias, A e B, geradas em fornos a carvão vegetal e mineral, respectivamente, com diferentes teores de alumina. A cura térmica também foi empregada como forma de intensificar a cinética de hidratação e aumentar as propriedades mecânicas. O objetivo foi contribuir sobre o entendimento da influência da composição química da escória em CSS, sobretudo, daquela gerada em fornos a carvão vegetal, cujos estudos são ausentes na literatura.

\section{MATERIAIS E MÉTODOS}

\subsection{Materiais}

\subsubsection{Escórias de alto forno}

A metodologia aplicada no preparo das escórias foi a mesma utilizada por RUBERT et al. [14], onde as mesmas foram inicialmente secadas em estufa ( 24 horas/temperatura controlada de $105{ }^{\circ} \mathrm{C}$ ) e depois trituradas em moinho de bolas. A composição química das escórias, identificada pela análise de Fluorescência de raios X (FRX), está apresentada na Tabela 1, onde ambas atendem aos requisitos exigidos pela norma europeia EN 15743 [7]. Percebe-se que a escória ácida $(\mathrm{A})$ possui um teor de alumina $\left(\mathrm{Al}_{2} \mathrm{O}_{3}\right)$ maior que a básica (B), o que é desejável para uso em CSS [5-6]. A escória A também apresenta uma superfície específica mais alta, o que propicia a reatividade.

Tabela 1: Composição química da escória gerada em forno a carvão vegetal (A) e a carvão mineral (B)

\begin{tabular}{cccc}
\hline Óxidos $(\%)$ & Escória A & Escória B & EN 15743 \\
\hline $\mathrm{SiO}_{2}$ & 38,1 & 32,2 & - \\
$\mathrm{Al}_{2} \mathrm{O}_{3}$ & 13,9 & 8,2 & - \\
$\mathrm{Fe}_{2} \mathrm{O}_{3}$ & 1,3 & 0,8 & - \\
$\mathrm{CaO}$ & 37,0 & 49,5 & - \\
$\mathrm{MgO}$ & 6,2 & 5,0 & - \\
$\mathrm{SO}_{3}$ & 0,1 & 1,4 & - \\
$\mathrm{Na}_{2} \mathrm{O}$ & 0,2 & 0,1 & - \\
$\mathrm{TiO}_{2}$ & 0,8 & 0,6 & - \\
$\mathrm{MnO}$ & 1,1 & 1,3 & - \\
$\mathrm{CaO}+\mathrm{MgO}_{\mathrm{SiO}}$ & 81,3 & 86,7 & $\geq 66,7$ \\
$\left(\mathrm{CaO}+\mathrm{MgO}_{2} / \mathrm{SiO}_{2}\right.$ & 1,1 & 1,7 & $\geq 1,0$ \\
$\mathrm{CaO} / \mathrm{SiO}$ & & 1,54 & - \\
Superfície Específica $\left(\mathrm{cm}^{2} / \mathrm{g}\right)$ & 5120 & 4410 & - \\
\hline
\end{tabular}

A análise de difração de raios X (DRX) apresentada na Figura 1 permite observar que ambas as escórias possuem estrutura vítrea, contribuindo para a sua reatividade no sistema cimentício. 


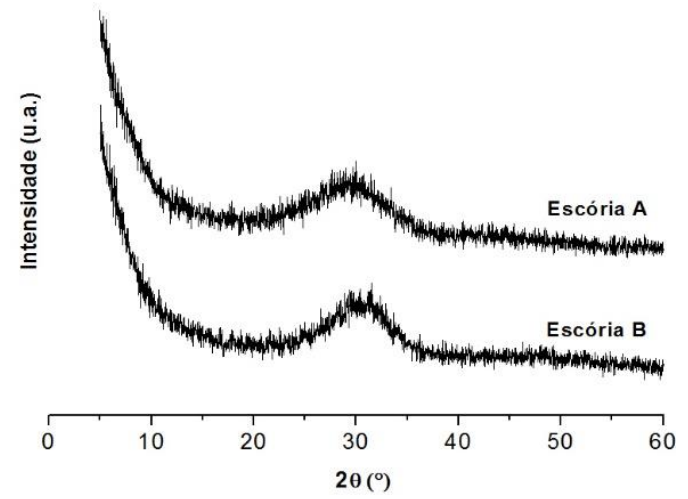

Figura 1: Difratogramas de Raios X da escória ácida (A) e básica (B).

\subsubsection{Sulfato de cálcio e ativador alcalino}

A fonte de sulfato de cálcio utilizada para preparação do CSS foi a anidrita $\left(\mathrm{CaSO}_{4}\right)$, resultante da calcinação da gipsita $\left(\mathrm{CaSO}_{4} \cdot 2 \mathrm{H}_{2} \mathrm{O}\right)$, a qual também foi triturada, moída em moinho de bolas durante 1 hora. $\mathrm{O}$ material obtido passou por peneiramento em malha com abertura de $150 \mu \mathrm{m}$ e então calcinado em mufla a uma temperatura de $650{ }^{\circ} \mathrm{C}$ por 60 minutos com taxa de aquecimento de $50{ }^{\circ} \mathrm{C} / \mathrm{min}$, conforme trabalhos recentes $[6,14$, 15]. A confirmação da forma anidra foi realizada através de DRX e apresentada na Fig. 2.

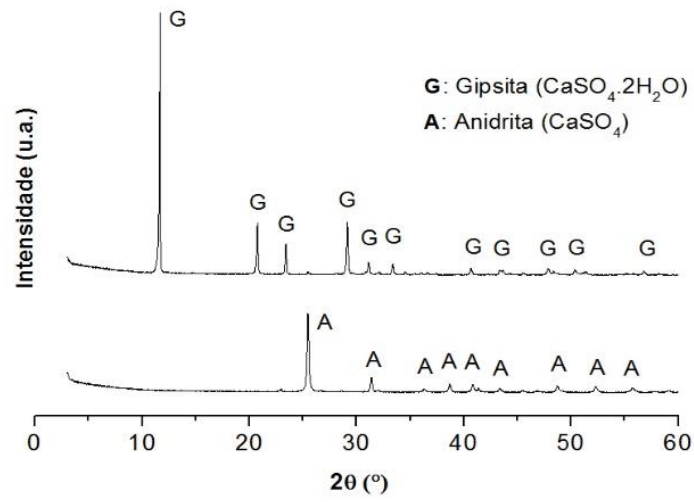

Figura 2: Difratogramas da gipsita (G) e da anidrita (A).

O hidróxido de potássio $(\mathrm{KOH}, 90 \%$ de pureza) foi empregado como ativador e não passou por nenhum tipo de tratamento prévio. A escolha foi baseada no trabalho de RUBERT et al. [14].

\subsection{Métodos}

A proporção de escória/anidrita empregada foi de 85/15 e foi baseada no trabalho de RUBERT et al. [14]. A variação ocorreu apenas na porcentagem do $\mathrm{KOH}$, pois a partir de testes prévios observou-se que a escória ácida precisou de um teor mais alto de ativador para alcançar a pega, conforme exibido pela Tabela 2.

Tabela 2: Proporção dos materiais na obtenção do aglomerante CSS.

\begin{tabular}{ccccc}
\hline TIPO ESCÓRIA & PROPORÇÃO & ESCÓRIA & ANIDRITA & ATIVADOR \\
\hline Ácida (A) & $85 \_15 \_2,0$ & $85 \%$ & $15 \%$ & $2,0 \%$ \\
Básica (B) & $85 \_15 \_0,5$ & $85 \%$ & $15 \%$ & $0,5 \%$ \\
\hline
\end{tabular}

A análise da resistência foi feita em argamassa, na proporção de 1: 2,75: 0,485 (aglomerante, areia e água) a qual foi baseada na literatura $[6,14,15]$. Foram moldados os corpos de prova em moldes prismáticos $(4 \times 4 \times 16 \mathrm{~cm})$, com desmoldagem após 24 horas e cura imersa em solução saturada de água e hidróxido de cálcio na concentração de $3 \mathrm{~g} / \mathrm{L}$ até as idades de 7 e 28 dias. Para cada idade, foram ensaiados três corpos de 
prova.

A análise da microestrutura foi realizada em pastas, com relação a/c de 0,4 , também baseada nos trabalhos recentes de cimentos supersulfatados [6, 14, 15,16]. As pastas também foram desmoldadas após 24 horas e imersas em solução de hidróxido de cálcio até as idades de 7 e 28 dias.

As condições de cura para as argamassas e pastas foram baseadas no trabalho de ANGULSKI DA LUZ e HOOTON [6], e denominadas Cura 1 e Cura 2:

- Cura 1: cura úmida (umidade relativa superior a $95 \%$ ) à $23{ }^{\circ} \mathrm{C}$ durante 24 horas seguida de cura submersa nas temperaturas de estudo $\left(15^{\circ} \mathrm{C}, 23^{\circ} \mathrm{C}\right.$ e $\left.40^{\circ} \mathrm{C}\right)$, até as idades de 7 e 28 dias.

- Cura 2: cura úmida (umidade relativa superior a 95\%) às temperaturas de estudo $\left(15^{\circ} \mathrm{C}, 23{ }^{\circ} \mathrm{C}\right.$ e $\left.40{ }^{\circ} \mathrm{C}\right)$ durante 24 horas seguida de cura submersa nessas mesmas temperaturas, até as idades de 7 e 28 dias.

Para a investigação da microestrutura das pastas cimentícias, a interrupção do processo de hidratação foi realizada por troca de solvente, através de imersão em acetona por 2 horas. Em seguida, o material foi filtrado, triturado e peneirado na malha $0,150 \mathrm{~mm}$. Antes da trituração uma pequena porção de amostra foi separada para análise de microscopia eletrônica de varredura (MEV). Para as análises de difração de raios X (DRX) foi utilizada radiação CuKa, intervalo de leitura $2 \theta$ de $3^{\circ}-70^{\circ}$, passo de $0,02^{\circ}$. Na análise de calorimetria exploratória por condução (DSC) os parâmetros utilizados foram atmosfera inerte de gás N2 com fluxo de $100 \mathrm{~mL} \mathrm{~min}^{-1}$, taxa de aquecimento de $10^{\circ} \mathrm{C} \mathrm{min}^{-1} \mathrm{em}$ uma faixa de leitura de 30 a $300{ }^{\circ} \mathrm{C}$, conforme GRACIOLI et al. [15].

\section{RESULTADOS E DISCUSSÃO}

\subsection{Resistência à compressão}

Os resultados para os ensaios de resistência à compressão são apresentados na Fig. 3.
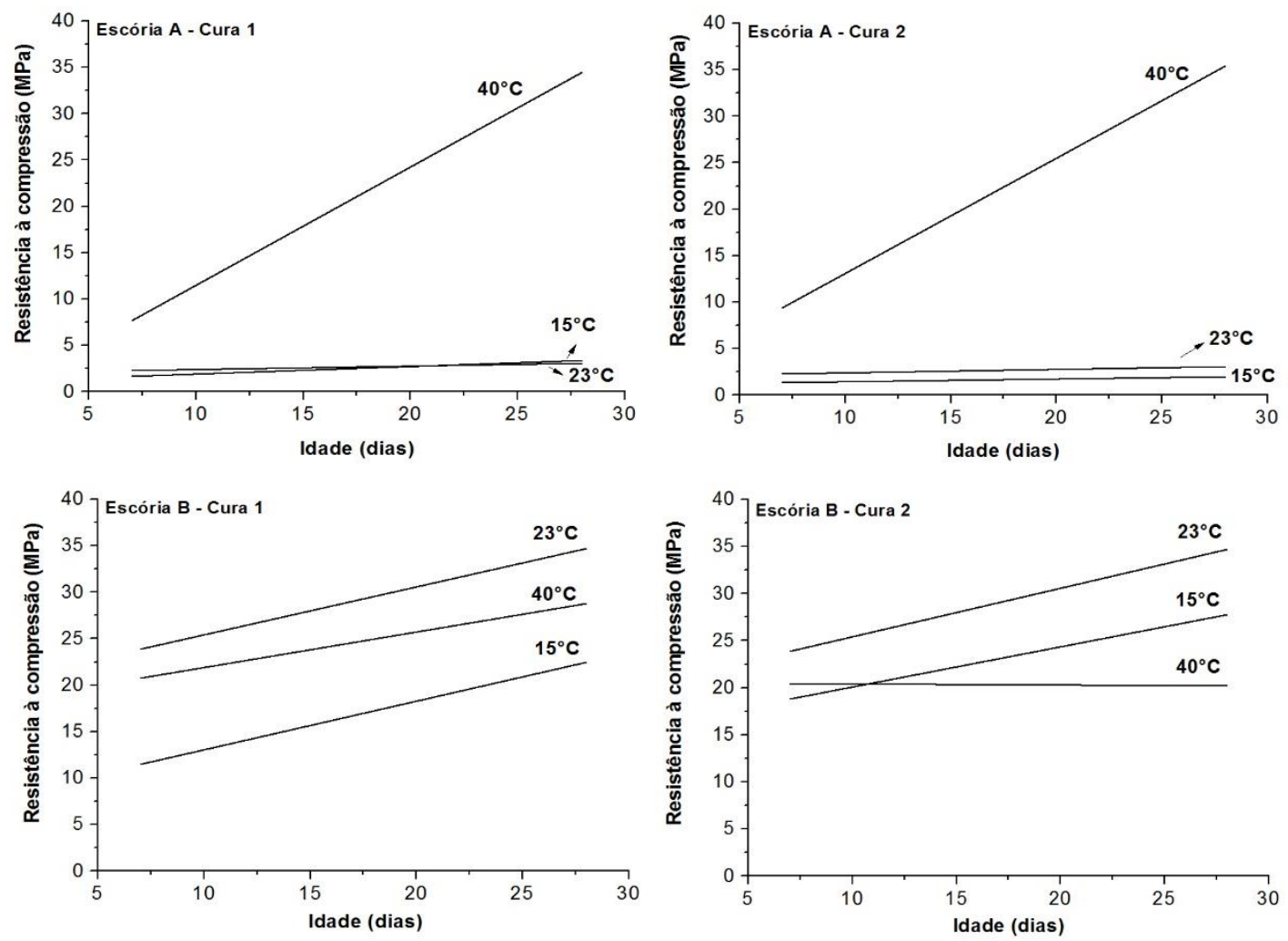

Figura 3: Resistência à compressão de argamassas de CSS feitas com escória ácida e básica nas condições de cura 1 e 2.

As argamassas de CSS feitas com escória ácida (A) alcançaram resistências baixas (menor que 5 $\mathrm{MPa}$ ) quando submetidas às temperaturas de 15 e $23{ }^{\circ} \mathrm{C}$. No entanto, à temperatura de $40{ }^{\circ} \mathrm{C}$, aos 28 dias, as amostras atingiram valor superior a $30 \mathrm{MPa}$. Percebe-se que a temperatura influenciou significativamente o resultado enquanto que o tipo de cura não.

As argamassas de CSS feitas com escória básica (B) alcançaram resistências de no mínimo 20 MPa, 
independente da temperatura e do regime de cura. $\mathrm{O}$ maior desempenho ocorreu à $23{ }^{\circ} \mathrm{C}$ onde, aos 28 dias, o valor também foi superior a $30 \mathrm{MPa}$. O comportamento nas demais temperaturas foi alterado pelo tipo de cura. Naquela onde as amostram aguardaram 24 horas antes de serem submetidas à 15 e à $40{ }^{\circ} \mathrm{C}(\mathrm{Cura} 1)$, os resultados foram maiores na temperatura mais elevada. Já, na Cura 2, quando as argamassas foram submetidas à 15 e à $40^{\circ} \mathrm{C}$ logo após a moldagem, os valores foram semelhantes aos 7 dias, mas superior na temperatura $15^{\circ} \mathrm{C}$ aos 28 dias.

O comportamento das argamassas de CSS foi semelhante àquele investigado por ANGULSKI DA LUZ e HOOTON [6] quando também adotaram condições similares de cura para CSS feitos com escórias distintas. Os autores observaram que para a escória menos reativa $\left(\right.$ à $\left.23{ }^{\circ} \mathrm{C}\right)$, neste caso a escória A, temperaturas mais altas promoveram maiores resistências mecânicas, embora o aumento tenha sido bem menos intenso que o observado neste trabalho. Já, para a mais reativa (escória B), temperaturas mais altas $\left(40{ }^{\circ} \mathrm{C}\right)$ promovem resistências mais baixas quando submetidas ao sistema de cura 2, ou seja, sem esperar 24 horas. Os autores atribuíram este comportamento à solubilidade do sulfato de cálcio, a qual é mais baixa em temperaturas maiores, fazendo com que o mesmo fique indisponível para reagir com a escória para formar etringita, que é um dos principais compostos de hidratação do cimento supersulfatado.

\subsection{Investigação da microestrutura}

Os difratogramas exibidos pela Figura 4 mostram as fases consumidas e formadas para o CSS feito com escória ácida e básica, aos 7 e 28 dias, no regime de cura 1 e 2, onde destacam-se os picos relativos à fase anidra (anidrita) e aos produtos hidratados (etringita, gipsita e CSH).

Em relação ao CSS feito com escória ácida, dos 7 para 28 dias, percebe-se a redução do pico da anidrita (principal em $11,6^{\circ}$ ), mas que ainda permanece intenso na idade mais tardia, principalmente aos $40{ }^{\circ} \mathrm{C}$, independentemente do tipo de cura (1 ou 2). Este comportamento é explicado pela baixa solubilidade do sulfato de cálcio em temperaturas mais altas, conforme relatado por ANGULSKI DA LUZ e HOOTON [6], tornando-o menos disponível para a formação da etringita, ou mesmo da gipsita secundária. Os picos de gipsita secundária (principal em $11,6^{\circ}$ ) nas temperaturas de 15 e $23{ }^{\circ} \mathrm{C}$ confirmam a maior solubilidade do sulfato de cálcio nestas temperaturas. Os picos pequenos de etringita (principal em $9,1^{\circ}$ ), no entanto, revelam que a disponibilidade de sulfato de cálcio não foi suficiente para formação da fase, evidenciando a baixa reatividade da escória, independente do regime de cura (1 ou 2) e da temperatura. A presença de CSH mais cristalino é destacado pelo pico bem definido em $26,6^{\circ}$, para a temperatura de $23{ }^{\circ} \mathrm{C}$, e em $29,4^{\circ}$, concomitante com a gipsita, dificultando a análise desta fase por DRX.

Em relação ao CSS feito com escória básica, podem ser observados picos mais intensos de etringita, em comparação ao CSS feito com escória ácida. Nestas amostras, a formação da etringita é maior em temperaturas mais baixas, possivelmente influenciada pela maior disponibilidade (solubilidade) do sulfato de cálcio. Os picos de gipsita são evidentes apenas aos 28 dias, à $15^{\circ} \mathrm{C}$. O consumo da anidrita (para a formação de gipsita ou etringita) foi menor em temperaturas mais altas; a temperatura de $40{ }^{\circ} \mathrm{C}$ foi nociva à formação de etringita, principalmente a condição de cura 2 (sem o repouso de $24 \mathrm{~h}$ à $23{ }^{\circ} \mathrm{C}$ ), exatamente como observado por ANGULSKI DA LUZ e HOOTON [6].

De forma geral, pode-se notar que a formação da etringita no CSS feita de escória A (menos reativa) foi pouco influenciada pelas condições de cura, diferente da escória B, que apresentou maior formação em temperaturas mais baixas. A formação da etringita, que é uma das principais fases o CSH, no entanto, não pode ser relacionada diretamente com a resistência mecânica, com exceção do CSS com escória básica, à $40{ }^{\circ} \mathrm{C}$, cura 2 , onde foram observados os menores valores de resistência e menor formação de etringita. 

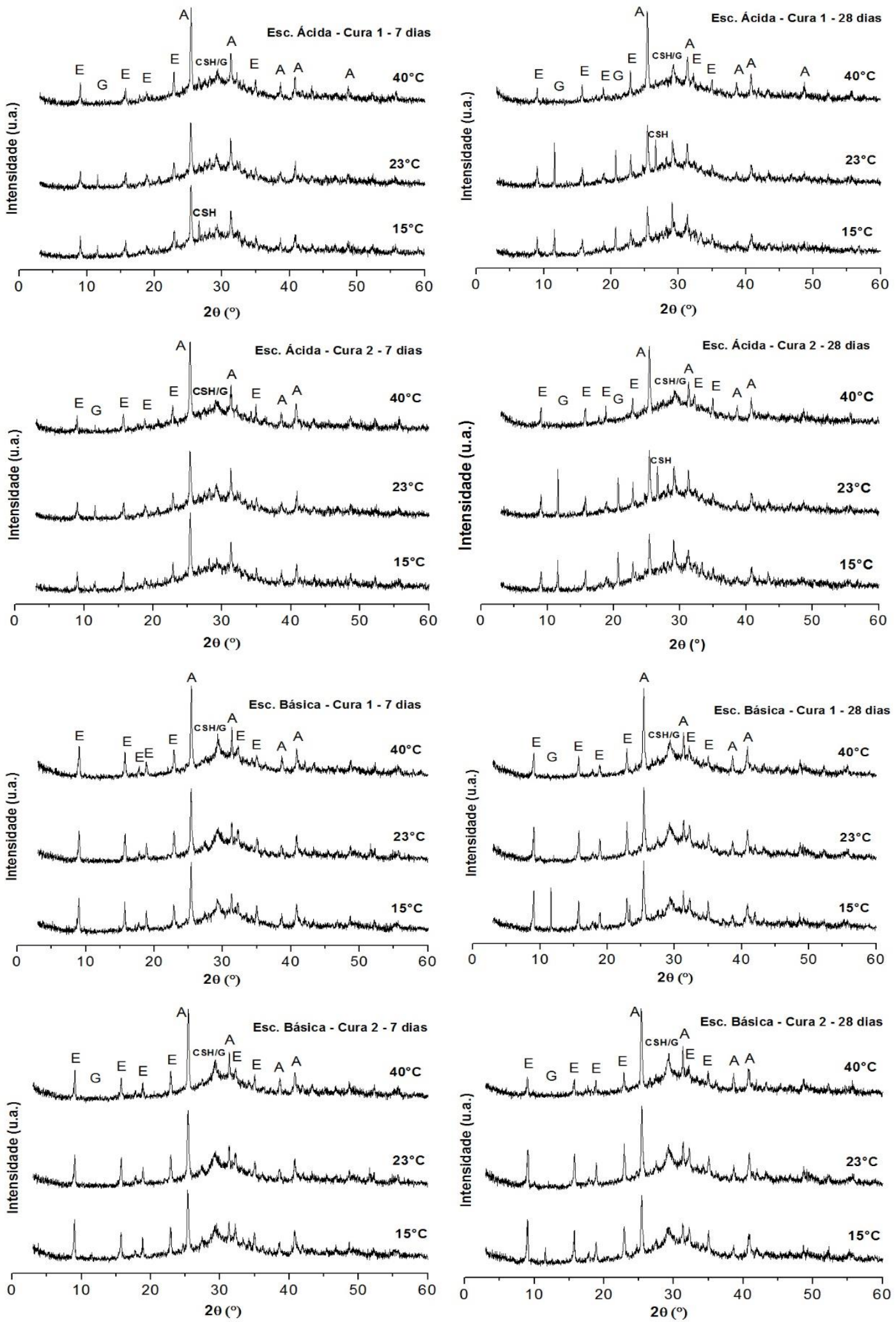

Figura 4: DXR das pastas de CSS feitas com escória ácida e básica nas condições de cura 1 e 2.

$$
\text { E= Etringita; } \mathrm{G}=\text { Gipsita, } \mathrm{A}=\text { Anidrita } ; \mathrm{CSH}=\text { Silicato de cálcio hidratado }
$$

Através das análises de DSC (calorimetria exploratória diferencial), Figura 5, são identificados picos referentes à presença de $\mathrm{CSH}$, entre 70 e $90^{\circ} \mathrm{C}$, etringita, entre 100 e $110^{\circ} \mathrm{C}$, e gipsita, entre 130 e $140{ }^{\circ} \mathrm{C}$.

Para o CSS feito com escória ácida, não foi observada diferença significativa entre os regimes de cura 1 e 2 , somente entre as idades e as temperaturas. A formação de gipsita secundária foi maior à 15 e à $23{ }^{\circ} \mathrm{C}$, 
como também constatado nos difratogramas. Já, a maior formação de $\mathrm{CSH}$ foi à $40{ }^{\circ} \mathrm{C}$. Isto atribui ao CSH o fato da argamassa curada nesta mesma temperatura ter alcançado maior valor de resistência mecânica.

Para o CSS feito com escória básica, são observados picos mais intensos, evidenciando maiores quantidades de fases hidratadas, conforme também constatado nos difratogramas. A influência negativa da temperatura à $40{ }^{\circ} \mathrm{C}$ na formação da etringita também é confirmada pelas análises térmicas. A formação de CSH também é menor em temperaturas mais altas, o que justifica resistência mais elevadas obtidas à $23^{\circ} \mathrm{C}$.
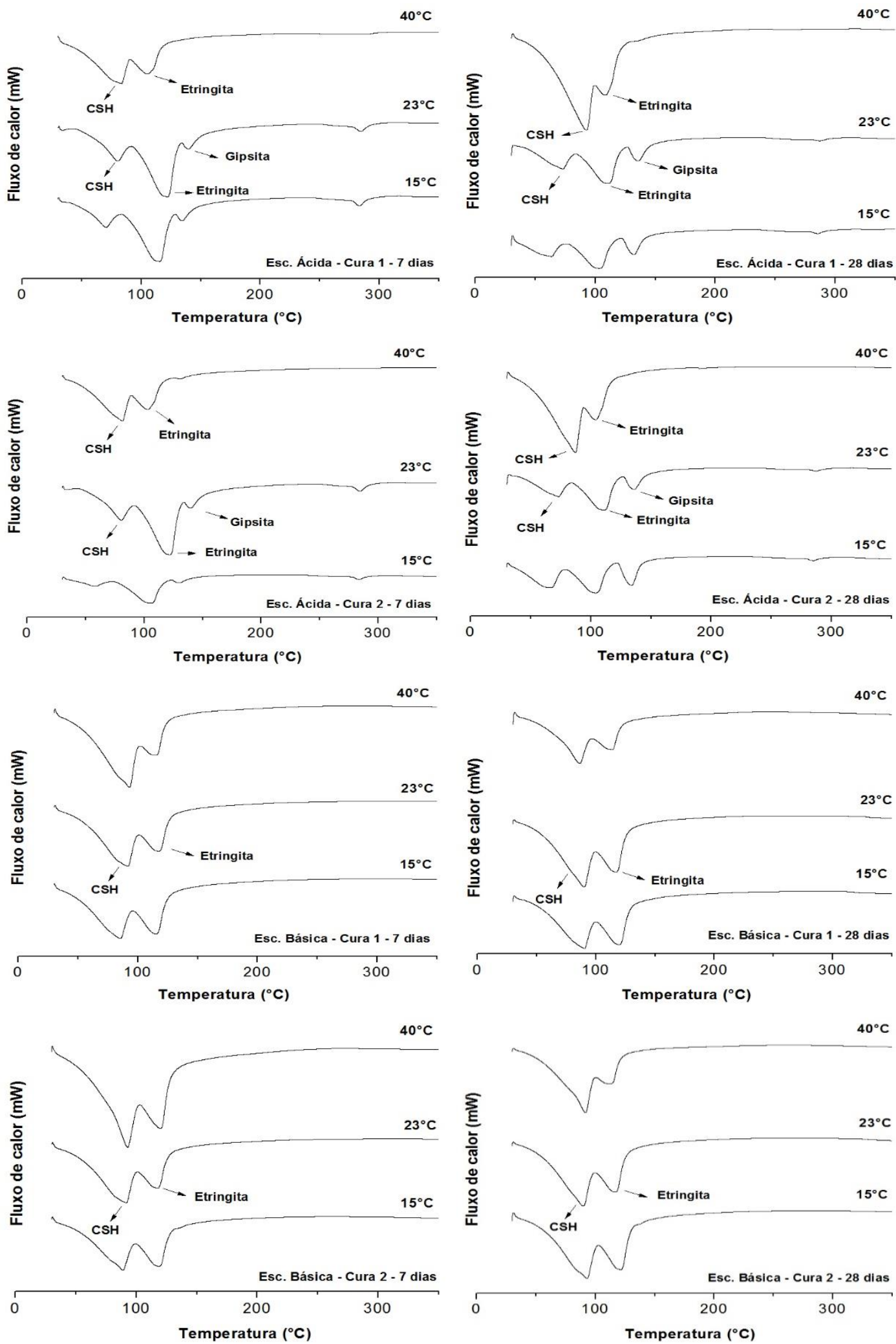

Figura 5: DSC das pastas de argamassa de CSS feitas com escória ácida e básica nas condições de cura 1 e 2. 


\section{CONCLUSÕES}

Neste trabalho, dois tipos de escória obtidas em fornos a carvão vegetal e mineral, consideradas ácida (tipo A) e básica (tipo B), respectivamente, foram empregadas em cimentos supersulfatados (CSS). Com objetivo de aumentar a resistência mecânica, as amostras foram sujeitas a dois tipos de cura, 1 e 2, ambos à 15, 23 e $40{ }^{\circ} \mathrm{C}$. Os resultados mostraram que:

- A escória A, gerada em forno a carvão vegetal, que tinha maior teor de alumina (13\%) se mostrou menos reativa e proporcionou às argamassas valores de resistência muito inferiores à $\mathrm{B}$, com exceção da condição de cura à $40^{\circ} \mathrm{C}$, onde obteve valores similares. Nesta temperatura, o ganho de resistência foi atribuído à maior formação de $\mathrm{CSH}$. O efeito da condição de cura foi condizente ao observado pela literatura para escórias menos reativas (baixa resistência à $23{ }^{\circ} \mathrm{C}$ );

- As argamassas produzidas com escória B, com baixo teor de alumina (8\%), que se mostrou mais reativa, tiveram comportamento mecânico e microestrutura fortemente influenciada por ambos, tipo e temperatura de cura. A formação da etringita foi maior em temperaturas mais baixas; a temperatura de $40^{\circ} \mathrm{C}$ foi nociva à sua formação (e à resistência à compressão), principalmente na condição de cura 2 (sem o repouso de $24 \mathrm{~h}$ à $23^{\circ} \mathrm{C}$ ), conforme também observado pela literatura para escórias mais reativas;

- Embora as escórias A e B tenham atendido às condições exigidas pela norma EN 15743, apenas a B, com menor teor de alumina (8\%), se mostrou adequada para a produção de CSS, pelo menos, nas proporções consideradas neste estudo. Os resultados mostraram que o alto teor de alumina presente na escória A e/ou o seu atendimento à EN 15743 não foram suficientes para garantir a resistência mecânica do CSS. É provável que o baixo teor de cálcio em escórias ácidas seja insuficiente para proporcionar a formação de CSH e etringita, porém, mais investigações são necessárias.

\section{AGRADECIMENTOS}

Os autores agradecem ao CNPq pelo apoio financeiro (Edital Universal 2013, processo 483661/2013-9).

\section{BIBLIOGRAFIA}

[1] ASSOCIAÇÃO BRASILEIRA DE NORMAS TÉCNICAS. NBR 5735. Cimento Portland - Requisitos. Rio de Janeiro, 12 p., 2018.

[2] AMERICAN SOCIETY FOR TESTING AND MATERIALS. ASTM C989/C989M: Standard Specification for Slag Cement for Use in Concrete and Mortars. Estados Unidos, 8 p., 1999.

[3] BRITISH STANDARD INSTITUTION. BS 6699. Specification for ground granulated blast furnace slag for use with Portland cement. 22 p., 1992.

[4] LANGARO, E., ANGULSKI DA LUZ, C., MORAES, M. C., et al., "A influência da composição química e da finura no desempenho de cimentos álcali ativados obtidos com escórias de alto forno", Revista Matéria-Rio de Janeiro, v. 22, pp. 1-11, 2017.

[5] GRUNSKOVNJAK, A., LOTHENBACH, B., WINNEFELD, F., et al., "Hydration mechanisms of super sulphated slag cement", Cement and Concrete Research, v. 38, n. 7, pp. 983-992, 2008.

[6] ANGULSKI DA LUZ, C., HOOTON, R. D., "Influence of curing temperature on the process of hydration of supersulfated cements at early age", Cement and Concrete Research, v. 77, pp. 69-75, 2015.

[7] NORMA EUROPEIA. EN 15743. Supersulfated cement - Composition, specifications and conformity criteria. 2010.

[8] JUENGER, M. C. G., WINNEFELD, F., PROVIS, J., IDEKER, J. H., "Advances in alternative cementitious binders", Cement and Concrete Research, pp. 1232-1243, 2011.

[9] GROUNDS, Z., NOWELL, D. V., WILBURN, F. W., "The influence of temperature and different storage conditions on the stability of supersulphated cement", Journal of Thermal Analysis and Calorimetry, v. 41, pp. 687-699, 1994.

[10] DING, S., SHUI, Z., CHEN, W., et al., "Properties of Supersulphated Phosphogypsum-Slag Cement (SSC) Concrete", Journal of Wuhan University of Technology - Materials Science, pp.109-113, 2014.

[11] COUTO C., ALMEIDA, J. A., PINTO, J. D. S., et al., "Influência da pozolanicidade da escória de alto forno nas propriedades de argamassa e concretos duráveis", Revista Construindo, v. 2, n.1, pp. 31-34, 2010.

[12] SOUZA JUNIOR, D. S., Estudo do comportamento de escórias de alto forno a carvão vegetal produzi- 
das a partir de ativação à quente, Tese de M.Sc., Universidade Federal de Minas Gerais, Belo Horizonte, 2007.

[13] SANTOS, A. P., SOTILES, A. R., ANGULSKI DA LUZ, C., et al., "Uso de escórias de alto forno produzidas em fornos a carvão vegetal em cimentos do tipo Portland", In: II Congresso Luso Brasileiro de Materiais de Construção Sustentáveis, João Pessoa, 2016.

[14] RUBERT, S., ANGULSKI DA LUZ, C., VARELA, M. V. F., et al., "Hydration mechanisms of supersulfated cement", Journal of Thermal Analysis and Calorimetry, v. 1, pp. 1-10, 2018.

[15] GRACIOLI, B., VARELA, M. V. F., BEUTLER, C. S., et al., "Considerações sobre a resistência mecânica e o processo de hidratação de cimentos supersulfatados (CSS) formulados com fosfogesso", Revista Matéria (UFRJ), v. 22, pp. 1-10, 2017.

[16] ANGULSKI DA LUZ, C., HOOTON, R. D., "Influence of Supersulfated Cement Composition on Hydration Process", Journal of Materials in Civil, v. 31(6), pp. 1-6, 2019.

\section{ORCID}

Cheila Sirlene Beutler

https://orcid.org/0000-0001-5828-3670

Caroline Angulski da Luz https://orcid.org/0000-0002-8007-1620

Janaina Sartori Bonini https://orcid.org/0000-0003-1252-1893 